\title{
Dönel kavşaklarda meydana gelen dengesiz akımlara bir çözüm önerisi olarak kısmi denetimli sinyalize dönel kavşaklar: Bir literatür araştırması
}

\section{Roundabout metering as a solution proposal to roundabouts with unbalanced flows: A literature study}

\author{
Hakan Ordu1,* (D), Ufuk Kırbaş ${ }^{2}$ \\ ${ }^{1}$ Karayolları Genel Müdürlüğü, Strateji Geliştirme Daire Başkanllğı, Stratejik Planlama Şube Müdürlüğü, 06100, Ankara, Türkiye \\ 2. Ondokuz Mayls Üniversitesi, İnşaat Mühendisliği Bölümü, 55139,Samsun, Türkiye
}

\begin{abstract}
Özet
Karayolu ağlarında büyük öneme sahip olan kavşaklar, çeşitli özelliklerine göre kategorilere ayrılır. Hemzemin kavşak tiplerinden biri olan dönel kavşaklar yirminci yüzyılın başından itibaren kullanılmaktadır. Modern dönel kavşaklar, ada etrafinda dönen araca yol ver kuralı ve yüksek güvenliğe sahip geometrisi ile yaklaşım kollarından katılan araçların düşük ve sabit hızla hareketini sağlar. Bu nedenle modern dönel kavşaklar, son yıllarda özellikle kentsel kavşaklarda tercih edilmektedir. Ancak bu kavşak tipi, yaklaşım kollarındaki dengesiz akımlara karşı hassas olduğundan, bu şartlar altında kavşağa katılmak isteyen araçlar arasında gerekli olan boşluğu sağlayamaz ve kavşak kollarında gecikmeler ve kuyruklanmalar oluşur. Meydana gelen aşırı gecikme ve kuyruklanma sorunlarının azaltılması amaciyla kısmi denetimli sinyalize dönel kavşaklar bir çözüm seçeneği olarak kullanılmaya başlanmıştır. Bu makalede, kısmi denetimli sinyalize dönel kavşakların kavşak performansı üzerindeki etkisi mevcut literatür 1şı̆̆ında incelenmiştir. Bu çalışmada dönel kavşakların performanslarını değerlendirmek için temel parametre olarak gecikme kullanılmış, ayrıca çevresel ve ekonomik etkilere de değinilmiştir. İncelenen çalışmalarda, kısmi denetimli sinyalize dönel kavşakların çeşitli akım talepleri altında başarılı sonuçlar verdiği görülmüştür. Bu sebeple kısmi denetimli sinyalize dönel kavşakların ülkemizde bulunan dönel kavşakların geometrileri ve yerel sürücü davranışları gibi değişkenler de göz önünde bulundurulması kaydıyla bir seçenek olarak değerlendirilmesi gerektiğinden bahsedilmiştir.
\end{abstract}

Anahtar kelimeler: Dengesiz akım, Dönel kavşak, Emisyon, Gecikme, Sinyalizasyon, Trafik simülasyonu, Yakıt sarfiyatı

\section{Giriș}

Ülkemizde ve dünyada hızlı bir şekilde artış gösteren nüfus ve buna paralel olarak gelişim gösteren ekonomik faaliyetler ve artan hususi araç sahipliği, ulaşım ağlarının da gelişmesine neden olmuştur. Böylece karayollarında seyreden araç sayısı da hızla artmıştır. Trafikte bulunan çok sayıdaki araç ve gelişen yol ağları, günümüz trafiğinin en çok sorun oluşan alanlarından birini de ortaya çıkarmıştır:

\begin{abstract}
Intersections have significant effect in highway networks and are categorized according to their various characteristics. Roundabouts, one of the types of at-grade intersections, have been using since the beginning of the twentieth century. Modern roundabouts are common in recent years, especially in urban intersections, thanks to the give way rule to circulating vehicles around the island and its geometry that provides high safety by ensuring low and constant speed movement of the vehicles joining from the approaches. However, this type of intersection is sensitive to unbalanced flow patterns in the approaches, it cannot provide the necessary gap to the vehicles that want to join the intersection under these conditions hence delays and queues occur in the intersection legs. In order to reduce emerged excessive delay and queuing problems, roundabout metering has started to be used as a solution option. In this article, the effect of roundabout metering on intersection performance is examined in the light of the available literature. In this study, delay was used as the primary parameter to evaluate the performance of roundabouts, also environmental and economic impacts were mentioned. In the investigated studies, it was seen that roundabout metering shows successful results under several flow patterns. Thus, it was mentioned that roundabout metering should be considered as an option by taking factors into account such as the geometry of the roundabouts in Turkey and local driver behaviors.
\end{abstract}

Keywords: Delay, Emission, Fuel consumption, Roundabout, signalisation, Traffic simulation, Unbalanced flow

Kavşaklar. Kavşaklar; iki veya daha fazla karayolunun kesiştiği, birleştiği veya ayrıldığı noktalar olarak tanımlanır. Ayrıca kavşaklar, bu yollar arasındaki dönüş hareketlerini de kapsamaktadır. Böylece daha az sayıda karayolu ile çok fazla erişim sağlanmaktadır. Kavşaklar; çeşitli özelliklerine göre yolun kapasitesi, hizmet seviyesi gibi birçok parametreyi doğrudan etkilediğinden karayolu ağları içinde çok önemli bir yer tutar [1]. Kavşaklar, farklı trafik akımlarının

\footnotetext{
* Sorumlu yazar / Corresponding author, e-posta / e-mail: hakanordu7@ gmail.com (H. Ordu)

Geliş / Recieved: 01.02.2021 Kabul / Accepted: 05.05.2021 Yayımlanma / Published: 27.07.2021

doi: 10.28948/ngmuh.872504
} 
birbiriyle etkileşime girdiği noktalar olduklarından trafik güvenliği yönünden de önem taşımaktadır. Karayolları Genel Müdürlüğü'nün yayımladığı Trafik Kazaları Özeti adlı rapora göre, 2019 yılında gerçekleşen 174.896 ölümlü ya da yaralanmalı kazanın 65.681 tanesi kavşaklarda meydana gelmiştir [2]. Bu da yaklaşık \%38'lik bir orana tekabül etmektedir. Amerika Birleşik Devletleri'nde ise ölümlü ve yaralanmalı kazaların yarısından fazlası kavşaklarda ya da kavşağa yakın noktalarda gerçekleşmektedir [3]. Avrupa Komisyonu'nun 2018'de yayımladığı Yıllık Kaza Raporu'na göre ise Avrupa Birliği ülkelerinde 2016 yılında yaşanan ölümlü trafik kazalarının yaklaşık \%15'i kavşak noktalarında gerçekleşmiştir [4]. Sayısal veriler de dikkate alındığında kavşakların gerek karayolu ağlarından sorumlu idareler gerek mühendisler gerekse de karayollarını kullanan sürücüler ve yayalar tarafından ne kadar önemli olduğu ortaya çıkmaktadır.

Karayolu ağlarının önemli bir parçası olan kavşaklar, temel olarak iki gruba ayrılabilir:

- Eşdüzey Kavşaklar

- Farklı Seviyeli Kavşaklar

Eşdüzey kavşaklar, iki veya daha fazla karayolunun aynı düzlemde kesişmesi sonucu oluşan kavşaklardır. Bu tip kavşaklarda dört çeşit trafik hareketi bulunabilir. Bunlar;
1. Ayrilma
2. Katılma
3. Kesişme
4. Örülme

olarak sıralanabilir [5].

Eşdüzey kavşaklarda oluşabilecek bu trafik hareketleri, trafik güvenliği adına risk oluşturabilmektedir. Bu sebeple eşdüzey kavşakların iyi bir şekilde tasarlanması büyük önem arz etmektedir. Bu sorunların ortaya çıkarabileceği kazaları azaltmak için eşdüzey kavşak çeşitlerinden biri olan dönel kavşaklar ön plana çıkmaktadır.

Dönel kavşaklar, araçların genellikle dairesel bir ada etrafında dönüp istedikleri yöne hareket etmelerini sağlayan eşdüzey kavşaklardır. Dönel kavşakların tarihine bakıldığında bu kavşak türü, ilk olarak 1905 yılında New York'ta kullanılmış ve ABD geneline yayılmıştır. Fakat trafik çemberlerinin yüksek hızlı katılma ve örülmelere müsaade etmesi, fazla kazanın yaşanması ve tıkanıklık gibi sorunlar nedeniyle 1950'lerin ortalarından itibaren gözden düşmüştür. Ancak 1960'larda Birleşik Krallık'ta ada etrafinda dönen araca yol ver kuralıyla birlikte modern dönel kavşaklar ortaya çıkmış, birçok ülkede yaygın olarak kullanılmaya başlanmıştır [6].

Modern dönel kavşaklar, trafik çemberleriyle kıyaslandığında bazı farklılıklar barındırır. AASHTO'nun [7] bahsettiği üzere bu farklar şu şekildedir:

1. Yol Ver: Yol ver kuralı, ada etrafında dönen araçların geçiş hakkına sahip olmasını ve yaklaşım kolundan katılacak tüm araçların dönen akımda bir boşluk beklemesini gerektirir. Serbest akımı ve yüksek kapasiteyi korumak için giriş kontrolü olarak yol ver tabelaları kullanılır.

2. Giriş Sapması: Modern dönel kavşaklarda hiçbir trafiğin dönel kavşak boyunca düz bir yol izlemesine izin verilmez. Bunun yerine giriş trafiği, merkez ada tarafından uygun bir kavis ile sağa saptırılır.
Modern dönel kavşaklar, geleneksel kavşak tasarımlarına göre daha az çakışma noktasına sahip olduklarından trafik güvenliğine pozitif etkide bulunmakta ve böylece kaza sayısını ciddi derecede azaltmaktadır. Şekil 1 ve Şekil 2'de, üç ve dört kollu modern dönel kavşakların ve geleneksel kavşakların çakışma noktaları gösterilmiştir. Şekil 1'de görüldüğü üzere dört modern dönel kavşaklar, geleneksel dört kollu kavşaklarda oluşan 32 çakışma noktasını 8'e indirmiştir. Şekil 2'de ise üç kollu modern dönel kavşaklar, geleneksel üç kollu kavşaklarda oluşan 9 çakışma noktasını ise 6'ya indirmiştir. Ayrıca, modern dönel kavşakların trafik kazalarına olan etkisi hakkında çeşitli çalışmalar yapılmış ve etkinlikleri değerlendirilmiştir. Çalışmalar incelendiğinde modern dönel kavşakların trafik kazalarını azaltma üzerinde önemli bir etkisi olduğu görülmüştür [9-11].

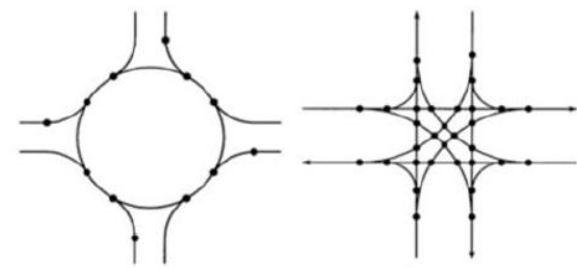

Şekil 1. Dört kollu bir dönel kavşak ve geleneksel bir dört kollu kavşakta çakışma noktaları [1]
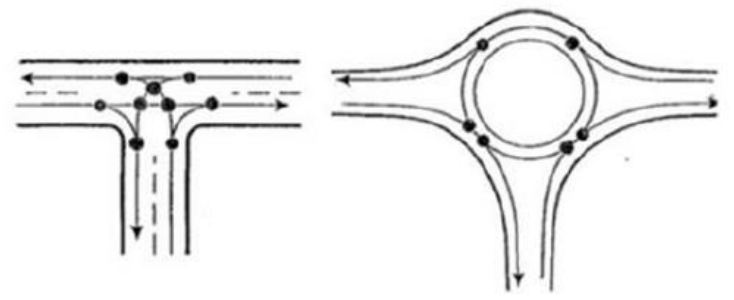

Şekil 2. Üç kollu bir geleneksel kavşak ve üç kollu bir dönel kavşakta çakışma noktaları [8]

\section{Dönel kavşaklarda dengesiz akım sorunu}

Modern dönel kavşaklar, sinyalize kavşaklara göre araçlar için daha az dur kalk ve kuyruklanma sağlayarak verimliliği, trafik güvenliğini ve çevresel faydaları artırır. Böylece işletim ve bakım maliyetlerini de düşürerek kavşak operasyonlarında iyileşme sağlar [12]. Ancak kavşak kollarındaki akım dengesiz olduğu durumlarda dönel kavşakta kapasite sorunu ortaya çıkabilir ve kapasiteyle beraber birçok parametre de etkilenebilir. Bu şartlar altında modern dönel kavşakların teorik faydaları ortadan kalkacaktır. Bu durum birçok araştırmacının da dikkatini çekmiş ve çeşitli çalışmalarda dönel kavşaklardaki dengesiz akım sorunundan bahsetmişlerdir.

Huddart [13], bir dönel kavşağın düzgün çalışmasının giriş akımları arasında makul bir denge olmasına bağlı olduğunu söylemiş, yaklaşım kollarındaki trafik akımlarında bu denge yoksa dönel kavşağın kapasitesinin sınırlı olduğunu ve bu durumun özellikle bir yaklaşım kolundan gelen yoğun ve kesintisiz bir trafik akımına bu koldan hemen önceki kolda hafif bir trafik akımı eşlik ediyorsa geçerli 
olduğundan bahsetmiştir. Ayrıca kesintisiz ama çok yoğun olmayan bir sirkülasyon trafiğinin, belirli bir yaklaşım kolundaki akımın kavşağa katılımını önemli bir şekilde engelleyecek bir başka durum olduğunu da belirtmiştir.

Krogscheepers ve Roebuck [14], dönel kavşaklarda dengesiz akımın tipik bir uygunsuz durum olduğundan bahsetmiştir ve şöyle açıklamıştır: "Bir kavşak yaklaşımındaki trafik hacminin, araçların başka bir yaklaşımdan kavşağa girişini etkin bir şekilde engelleyecek kadar yüksek olduğu durumdur. Bu koşullar altında, dönel kavşağı kullanmaya çalışan toplam trafik hacmi çok fazla olmayabilir, ancak yaklaşım kollarındaki hacimlerde bu büyük dengesizlik nedeniyle bazı kollarda aşırı gecikmeler ortaya çıkabilir". Ayrıca aynı çalışmada dengesiz trafik akımı durumunun sirküle olan akım tarafından oluşturulabileceğinden bahsedilmiş, dönel kavşaklardaki hareketlerin $\mathrm{T}$ kavşaklardaki gibi bağımsız olmadığı belirtilmiştir. Çalışmada, dengesiz akımı tanımlayacak bir formül geliştirilmiştir. Bu formüle göre dengesizlik rasyosu ( $\rho$ i) kuzey yaklaşım kolu için ( $\rho n)$ Denklem (1)'deki gibi hesaplanır:

$$
\rho_{n}=\frac{Q_{w n}}{Q_{w n}+Q_{s n}+Q_{e n}}=\frac{Q_{w n}}{Q_{n c}}
$$

$\mathrm{Q}_{\mathrm{nc}}=\mathrm{Q}_{\mathrm{wn}}+\mathrm{Q}_{\mathrm{sn}}+\mathrm{Q}_{\mathrm{en}}$

$\mathrm{Q}_{\mathrm{wn}}=$ batıdan kuzeye giden trafik

$\mathrm{Q}_{\mathrm{sn}}=$ güneyden kuzeye giden trafik

$\mathrm{Q}_{\mathrm{en}}=$ doğudan kuzeye giden trafik

Dengeli bir yaklaşım kolunda ( $\rho$ i) değeri 0,5 ' e eşit olur. Dengesiz akıma sahip kolda bu değer 0 veya 1 ' dir. Bu akımlar Şekil 3'te gösterilmiştir.

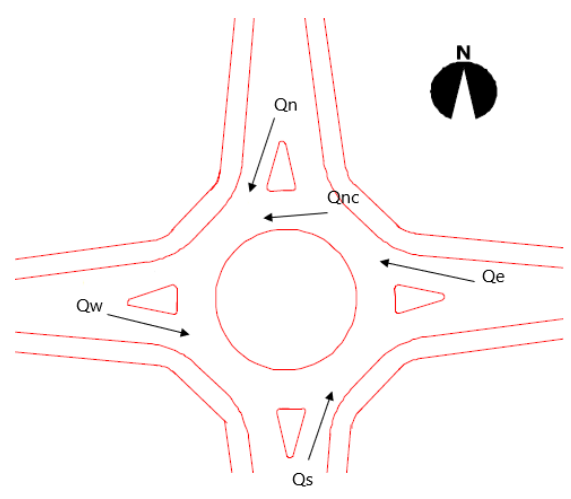

Şekil 3. Dengesiz akımların tanımı [14]

Tunç [15] bu konuyu şöyle açıklamıştır: “Anayolun trafik hacmi ve tali yoldaki trafik hacmi arasında çok büyük fark varsa, tali yoldan kavşağa giren araçlar örülme için yeterli aralık bulamayacak veya örülme trafiğinin artması ile anayol trafiğinde gecikmeler artacaktır”.
Akçelik [16] ise bu konu hakkında "Çoğunlukla tek bir yaklaşımdan kaynaklanan baskın sirküle akımlar, kavşağa giriş kapasitesini azaltır" ve "Dengesiz akımlar, genel talep seviyesi düşük olduğunda sorun olmayabilir, ancak sorun orta talep seviyelerinde bile ortaya çıar. Talep akım seviyeleri, bir dönel kavşağın uygulanmasından sonra, bazen nispeten kısa bir süre içinde önemli ölçüde değişebilir, çünkü sinyalize kavşaklardan farklı olarak dönüş hareketleri üzerinde doğrudan bir kontrol yoktur" demiştir.

Aydemir ve Tanyel [17], yaptıkları çalışmada "Yaklaşım kollarının birinden gelen akım talebinin diğer yaklaşım kollarına kıyasla fazla olması halinde bu durum kavşak kapasitesi üzerinde ciddi bir etkiye sahiptir" sonucuna varmıştır.

Batı Avustralya Karayolları İdaresi (MainRoads) [18], Kavşak Kontrolü Seçimi Rehberi'nde dengesiz akım sorununa yer vermiş ve dönel kavşakların performansının dengesiz akımlara karşı hassas olduğunu, bu durumun baskın bir yaklaşım kolundan gelen trafiğin başka bir yaklaşım kolunda bulunan trafiğin dönel kavşağa girmesini engellediği durumlarda oluşabileceğini ve bu şartlar altında kuyruklanma ve gecikme sorunlarının meydana gelebileceğini söylemiştir.

MainRoads'a [18], göre, dönel kavşakta dengesiz akım sorununu ortaya çıkaran baskın trafik akımı şunlardan biri olabilir:

-Kesintisiz, yoğun bir trafik akımı

-Tali yaklaşım kolundan gelip geçiş hakkını edinmiş olan, düşük ancak sürekli bir akım.

Akçelik'in [16] görselleştirdiği dengesiz akım kombinasyonlarına Şekil 4 'te yer verilmiştir:

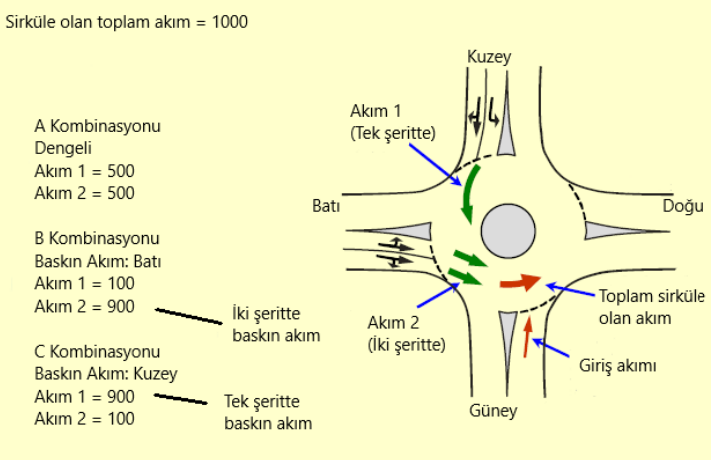

Şekil 4. Dengesiz akım kombinasyonları [16]

\section{Dönel kavşaklarda sinyalizasyon}

Dönel kavşaklarda oluşan dengesiz akım sonucu ortaya çıkan kapasite problemleri veya meydana gelen trafik güvenliği sorunlarını çözmek adına dönel kavşaklarda trafik 1şıkları kullanımı fikri ortaya çıkmıştır. Sinyalizasyon, dönel kavşakların doğasına uygun olmasa da dengesiz akım ve yüksek sirkülasyon hızı gibi problemlere çözüm olabilir. Stevens [19], çalışmasında dönel kavşakların sinyalizasyonunun kazanımlarını şu şekilde özetlemiştir:

-Daha kısa gecikmeler: Sinyalize olmayan dönel kavşaklardaki gecikmeler, dengesiz akımlar veya diğer 
kavşaklarla etkileşimler nedeniyle artar. Sinyalizasyon, gecikmeleri dengelemek için kullanılabilir.

-Daha kısa kuyruklar: Dengesiz akımla kuyruklar çok uzun hale gelebilir, bazen diğer kavşaklara veya yollara kadar uzayabilir. Sinyalizasyon, ilgili kola geçiş hakkı sağlayarak kuyrukları azaltabilir.

-Kapasitede artış: Aşırı miktarda trafik bir dönel kavşağa giriyorsa, trafik serbestçe dolaşamayabilir ve bazen kilitlenebilir. Trafiğin aşırı olduğu durumlarda, trafik sinyalleri bu durumu iyileştirebilir.

-Güvenlik: Dönel kavşaktaki sirkülasyon hızının yüksek olduğu durumlarda, diğer kollardaki araçlar kavşağa katılacak boşluğu bulamazlar. Trafik sinyalleri, dönel kavşağın girişini ve bazen çıkışını daha iyi düzenler, örülme ve katılma hızlarını azaltır, sürücülerin tepki vermesi için daha fazla zaman tanır ve dönel kavşakta güvenliği artırır.

Sinyalize dönel kavşaklar ilk olarak 1959 yılında İngiltere'de kullanılmış ancak kullanımı İngiltere'de özellikle 1990'dan sonra artış göstermiştir. Ayrıca dönel kavşakların sinyalizasyonu çeşitli şekillerde Hollanda, Almanya, İsveç, İrlanda, Belçika, Fransa, Türkiye, Danimarka, Slovenya, Polonya gibi Avrupa ülkelerinde, Amerika Birleşik Devletleri'nde ve Avustralya'da da kullanılmaktadır [20, 21]. Modern dönel kavşakların sinyalize olarak tasarlanması uygun bir durum olmasa da beklenmedik akım taleplerine karşı sinyalizasyon uygulanabilir [6].

Tablo 1'de, Hallworth'un [22], sinyalize dönel kavşaklar için kullanılan sinyalizasyon yöntemlerini özetlediği ve Natalizio [23] tarafindan tablolaştırılmış sınıflandırma gösterilmiştir.

Tablo 1. Dönel kavşak kontrol yöntemleri

\begin{tabular}{|c|c|c|}
\hline $\begin{array}{c}\text { Tasarim } \\
\text { Parametresi }\end{array}$ & Seçenek & Açıklama \\
\hline & Doğrudan & $\begin{array}{c}\text { Tüm iç ve dış yaklaşımların } \\
\text { sinyalizasyonu (Tüm çatışma noktaları } \\
\text { kontrol edilir) }\end{array}$ \\
\hline 1.Kontrol Çeşidi & Dolaylı & $\begin{array}{l}\text { Dış trafik yalnızca giriş noktasından } \\
\text { belli bir mesafedeki sinyallerle kontrol } \\
\text { edilir; sirküle olan trafik kontrol } \\
\text { edilmediğinden önceliği vardır }\end{array}$ \\
\hline 2.Tam & Tam & Sinyalizasyon daima çalışır \\
\hline $\begin{array}{l}\text { Zamanlı/K1smi } \\
\text { Zamanlı }\end{array}$ & Kismi & $\begin{array}{l}\text { Kısmi zamanlıdır, zamanlayıcı ya da } \\
\text { kuyruk detektörü vasıtasıyla açılır. }\end{array}$ \\
\hline 3.Tam & Tam & Tüm kollar sinyal kontrollüdür. \\
\hline $\begin{array}{l}\text { Kontrol/Kismi } \\
\text { Kontrol }\end{array}$ & Kısmi & $\begin{array}{l}\text { Bir ya da daha fazla kol öncelik } \\
\text { kontrollüdür. }\end{array}$ \\
\hline
\end{tabular}

Kavşak kollarının tamamının sinyalizasyonu yerine ö zellikle yoğun talep olan bir yaklaşım kolunda sinyalizasyon kullanmak çoğu durumda yeterli olabilir [19]. Bu şartlar altında kullanılmak amacıyla ortaya çıkan kısmi denetimli sinyalize dönel kavşaklar ile tüm kolların sinyalize edildiği bir kavşağa alternatif sunulmakta ve hem gereksiz gecikmeleri azaltmak hem de daha ekonomik bir çözüm yardimiyla mevcut problemlerin önlenmesi hedeflenmektedir. $\mathrm{Bu}$ yöntem özellikle Avustralya'da kullanılsa da Yeni Zelanda ve Amerika Birleşik Devletleri'nde de örnekleri mevcuttur [24-29].

\section{Kısmi denetimli sinyalize dönel kavşaklar}

Kısmi denetimli sinyalize dönel kavşaklar, dengesiz akımların neden olduğu aşırı kuyruklanma ve gecikmeleri sirküle olan akımda boşluklar oluşturarak engeller. Bu sayede geciken kol kavşağa katılabilir [30]. Özellikle sinyalizasyon ihtiyacı kısa süreli olduğunda geometrik iyileştirmelerden daha ekonomik bir çözüm olabilir [31]. Bu sebeple, kısmi denetimli sinyalize dönel kavşaklar genellikle yönsel akımların yoğunlaştığı zirve saatlerde kullanılır. VicRoads [32], bu yöntemin aşağıdaki faydaları sağladığını belirtmiştir:

1-) Makul öncelik paylaşımı için zirve akımların düzenlenmesi.

2-) Yaklaşım kolları arasında daha iyi kuyruk ve gecikme dengesi sağlama.

3-) Bir dönel kavşağın değiştirilmesi yerine ömrünü uzatma.

Ayrıca VicRoads [32], kısmi denetimli sinyalize dönel kavşaklar hakkında "Zaman içinde değişen trafik akımları nedeniyle sorunlar ortaya çıktığında kısa vadeli bir düzeltme aşaması olarak kabul edilirler ve bu sebeple belirli bölgelerde trafiği proaktif olarak yönetmek için yeni bir dönel kavşak kontrolünün parçası olabilirler” demiştir.

\subsection{Kısmi denetimli sinyalize dönel kavşak elemanları}

Kısmi denetimli sinyalize dönel kavşaklar, temel olarak iki bileşenden oluşur: Kuyruk detektörü ve sinyalizasyon. Kuyruk detektörü, aşırı gecikme ve kuyruklanmadan etkilenen yaklaşım koluna yerleştirilir ve bu kola kontrol kolu adı verilir. Bu detektör, tıkanıklık nedeniyle oluşan aşırı kuyruklanmanın oluşumunu tespit etmek için kavşağın girişinden belli bir mesafe geriye yerleştirilmelidir. $\mathrm{Bu}$ mesafe saha gözlemlerine göre değişebilecek olmakla birlikte, genellikle 50-120 m arasıdır. Kritik kuyruk uzunluğu algılandığında, kuyruk detektörü vasıtasıyla sinyalizasyon etkinleştirilir.

Sinyalizasyon, genellikle yoğun trafik akımının katılımını engelleyen yaklaşım koluna yerleştirilir ve bu kol da sinyalize kol olarak tanımlanır. Detektör ile etkinleştirilen sinyalizasyon sayesinde bu akıma kırmızı 1 şı yanar ve akımın kavşağa girişi engellenir. Böylece sirküle olan akımda boşluk oluşturulur ve gecikme yaşayan kolun kavşağa katılması sağlanır. Bu sayede dönel kavşaktaki ortalama gecikme azalır. Kırmızı 1şı söndüğünde ise dönel kavşak geleneksel halde yönetilir. Dönel kavşak girişinde bulunan yol ver tabelası ile trafik sinyalleri arasında yeterli boşluk sağlamak adına sinyalizasyon, dönel kavşak dur çizgisinden 15-20 m önce yerleştirilir, böylece sürücüde meydana gelebilecek kafa karışıklığı önlenmeye çalışılır [31, 33].

Kısmi denetimli sinyalize dönel kavşakların sinyalizasyonunda genellikle iki renkli sinyal kullanılır: Sarı ve kırmızı. Detektör, sinyalizasyonu etkinleştirdiğinde önce sarı 1şık sonra da kırmızı 1 şık yanar. Sinyalizasyonun gerekmediği zamanlarda hiçbir 1şık yanmaz (boş süre). Bazı saha uygulamalarında kırmızı 1şıkla birlikte yeşil 1 şı kullanılmıştır [27]. Ayrıca Yeni Zelanda Ulaştırma Ajansı da kısmi denetimli sinyalize dönel kavşakların sinyalizasyonunda yeşil ışığa yer vermiştir [34]. Ancak yeşil 
1şık, konvansiyonel sinyalizasyonda geçiş hakk1 anlamına geldiğinden sürücülerde kafa karışıklığ 1 yaratabilir. Çünkü bu sistem herhangi bir kola geçiş hakkı vermez. Araçlar kavşağa geldiklerinde modern dönel kavşak kurallarına uymak zorundadır. $\mathrm{Bu}$ sebeple yeşil $1 s ̧ ı \mathrm{k}$ kullanımında dikkatli olunmalıdır. Ayrıca yine kafa karışıklığını engellemek adına, sinyalizasyonun bulunduğu noktaya kırmızı 1şıkta dur tabelası yerleştirilir [18].

Boş sinyal süresi, minimum boş zaman gereksinimine göre belirlenir veya sinyalize yaklaşım kolunda detektör kullanılıyorsa sinyalize yaklaşım kolu trafiği tarafından uzatılır. Kırmızı sinyalin başlangıcı ve süresi ise kontrol yaklaşım kolu trafiği tarafından belirlenir. Akçelik [35] ve Fortuijn [36] çalışmalarında kısmi denetimli sinyalize dönel kavşaklar için sinyalizasyon operasyonunun detayları için yaklaşımlarını açıklamıştır. Akçelik [35], kısmi denetimli sinyalize dönel kavşakların süre analizinin SIDRA Intersection'da kullanılan genel sinyal süresi yöntemlerinin basit bir uygulaması olduğunu söylemiştir. Buna göre kısmi denetimli sinyalize dönel kavşaklarda devre süresi şu şekilde hesaplanır:

(2)

$$
c_{M}=F_{R}+F_{B}=T_{R}+I_{R}+T_{B}+I_{B}=R_{M}+G_{M}+t_{y B}
$$

$$
\begin{aligned}
& \text { TR = Denetleyici Kırmızı Süresi } \\
& \text { TB }=\text { Denetleyici Boş Süresi } \\
& F R=T R+I R=\text { Kırmızı Faz Süresi } \\
& \text { FB }=\text { TB }+ \text { IB = Boş Faz Süresi } \\
& \text { RM = Gösterilen Kırmızı Süre (sürücül } \\
& \text { önen) } \\
& \text { GM = TB = Gösterilen Boş Süre (sürü } \\
& \text { tyB = Boş Faz için Sarı Süre } \\
& \text { IR = Kırmızı Faz için Yeşillerarası Süre } \\
& \text { IB = Boş Faz için Yeşillerarası Süre. }
\end{aligned}
$$$$
\mathrm{RM}=\text { Gösterilen Kırmızı Süre (sürücüler tarafından }
$$
görünen)

$\mathrm{GM}=\mathrm{TB}=$ Gösterilen Boş Süre (sürücüler tarafindan görünen)

Fortuijn [36] ise sabit süreli kırmızı sinyal için şu formülü önermiştir:

$$
\text { RTsabit }=\left(\frac{L_{A D}}{L_{V}}\right) \times t_{F}+t_{C}-v_{r} / a_{0}
$$
(m)

LAD $=$ Talep detektöründen dönel kavşağa olan mesafe

LV = Kuyruktaki araçlar arasındaki ortalama mesafe (tampondan tampona) (m)

$\mathrm{tF}=$ Takip aralığı $(\mathrm{s})$

$\mathrm{tC}=$ Kritik boşluk $(\mathrm{s})$

$\mathrm{vr}=$ Dönel kavşaktaki hız $(\mathrm{m} / \mathrm{s})$

$\mathrm{a} 0=$ Hizlanma ivmesi. $(\mathrm{m} / \mathrm{s} 2)$

Önerilen bu formüller dışında sinyal süreleri için gerçek saha verilerini kullanarak dinamik çözümler sağlayan ve sabit bir devre süresi içermeyen adaptif (uyarlamalı) sinyalizasyon sistemleri kullanılabileceği gibi referans değerler göz önünde bulundurularak en iyi sonucu veren değerler de seçilebilir.

Kısmi denetimli sinyalize dönel kavşakların amacı kavşağın ortalama gecikmesini düşürmektir. Ancak kırmızı 1şık kullanımı sebebiyle sinyalizasyon kullanılan kolun gecikmesinin artacağı açıktır. Bu nedenle, sinyal sürelerinin ve detektörün kurulacağ önemlidir.

Şekil 5'te ve Şekil 6'da kısmi denetimli bir sinyalize dönel kavşak örneklerine yer verilmiştir.

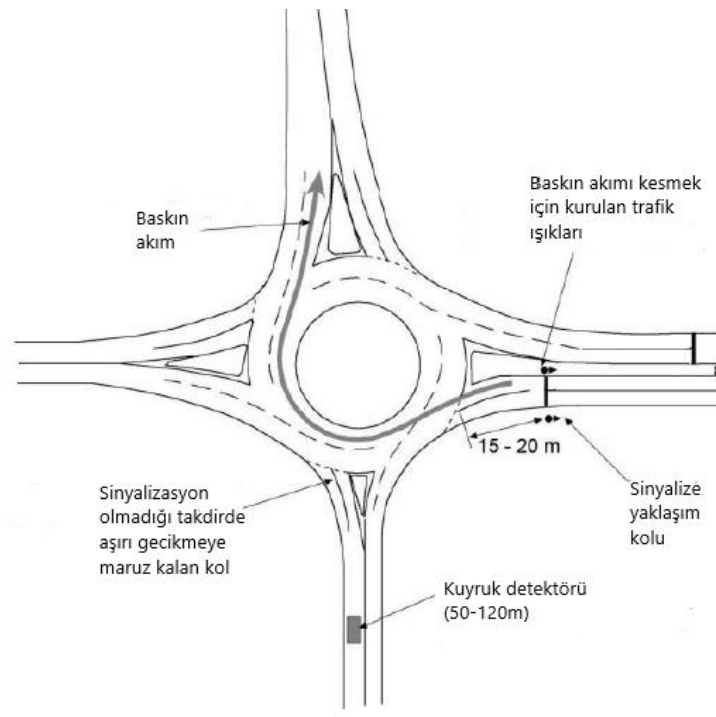

Şekil 5. Kısmi denetimli sinyalize dönel kavşak[37]

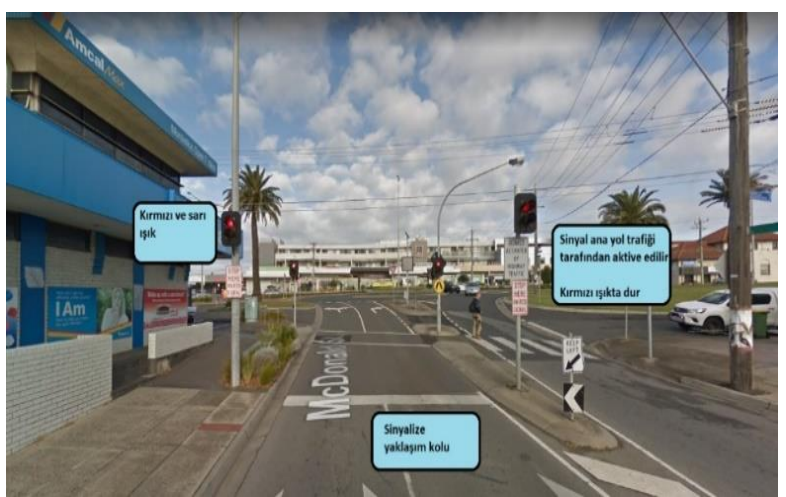

Şekil 6. Avustralya'da kısmi denetimli bir sinyalize dönel kavşak [38]

\section{Materyal ve yöntem}

Çalışmanın bu bölümünde, kısmi denetimli sinyalize dönel kavşaklar hakkında literatür taranmış ve incelenmiştir. Bu değerlendirmede, literatürde yer alan çalışmalar çeşitli özelliklerine göre sınıflandırılmış, bu çalışmalarda kullanılan programlardan bahsedilmiş, kısmi denetimli sinyalize dönel kavşakların gecikme üzerine etkisi ve ekonomik ve çevresel katkılarına yer verilmiştir.

\section{Kısmi denetimli sinyalize dönel kavşaklar üzerine yapılan çalışmalar}

\section{1 Çalışmalarda kullanılan programlar}

Kavşakların değerlendirilmesi adına piyasada birçok program bulunmaktadır. $\mathrm{Bu}$ programlar ile kavşakların performansları hakkında çok kapsamlı bilgiler edinilebilir. 
Söz konusu trafik analiz programlarını genel olarak iki gruba ayrırmak mümkündür. Bunlar;

1-) Analitik modeller

2-) mikro simülasyon modelleri [39]

Her iki grupta yer alan programlar trafik akım teorilerine dayanmaktadır. Ancak bu programlar analiz için farklı varsayımlar ve parametreler kullanır. Örneğin analitik bir model olan SIDRA değerlendirme için temel girdi olarak şerit kapasitelerini kullanırken; VISSIM, AIMSUN, PARAMICS gibi mikro simülasyonlarda yol kapasiteleri araç - sürücü - yol bileşeni etkileşim parametrelerine dayanır Tablo 2'de bu literatür araştırmasına konu olan çalışmalarda kullanılan programlara yer verilmiştir. Tabloda da görüldüğü üzere araştırmacılar çeşitli programlar kullanmıştır. Araştırmacılar her ne kadar çeşitli programlara yönelip değerlendirme adına farklı parametreler ve varsayımlar kullansalar da titiz bir biçimde kalibre edilmiş veriler kullandıkları taktirde bu programlar çok farklı sonuçlar sunmayacaktır [40].

Tablo 2. Çalışmalarda kullanılan programlar

\begin{tabular}{|c|c|}
\hline Çalışma & Program \\
\hline Akçelik[16, 25, 33, 35, 41] & $\begin{array}{l}\text { SIDRA } \\
\text { Intersection }\end{array}$ \\
\hline Abdelfatah ve Alozn[42] & $\begin{array}{l}\text { SIDRA } \\
\text { Intersection } \\
\text { aaSIDRA(Daha }\end{array}$ \\
\hline Natalizio [23] & $\begin{array}{l}\text { sonradan } \\
\text { SIDRA) }\end{array}$ \\
\hline An vd. [40, 43] & $\begin{array}{l}\text { Microsoft Excel } \\
\text { SIDRA } \\
\text { Intersection, } \\
\text { AIMSUN }\end{array}$ \\
\hline Mosslemi [44] & AIMSUN \\
\hline Geers vd. [45] & PARAMICS \\
\hline Fortuijn [36] & PTV VISSIM \\
\hline Buasali [46] & PTV VISSIM \\
\hline Hummer vd. [47] & $\begin{array}{l}\text { PTV VISSIM, } \\
\text { Synchro }\end{array}$ \\
\hline Martin-Gasulla vd. [48, 49] & PTV VISSIM \\
\hline Duan vd. [50] & PTV VISSIM \\
\hline Mahmood [51] & PTV VISSIM \\
\hline Ma vd. [52] & PTV VISSIM \\
\hline Fernandes vd. [53] & PTV VISSIM \\
\hline
\end{tabular}

\subsection{Dönel kavşakların özellikleri}

Dönel kavşaklar genellikle üç veya dört kollu tasarlanır ve genellikle dörtten fazla kollu olmaları tercih edilmez. Bu sebeple araştırmacılar da genellikle üç ya da dört kollu kavşaklar üzerinde çalışmışlardır. Ancak Sides [24], çok sayıda kavşağın yerine kurulan ve altı koldan oluşan Florida Clearwater Beach dönel kavşağında kısmi denetimli sinyalize dönel kavşak yöntemi kullanıldığını belirtmiş ve sayısal sonuçlara fazlaca yer vermese de muntazam bir başarı elde edildiğinden bahsetmiştir. Martin-Gasulla vd. $[48,49]$ çalışmalarında dört kollu bir dönel kavşağın yanı sıra lokal bir yola bağlanan ve çok az trafiği olan beşinci bir kola sahip bir dönel kavşağı da kullanmışlardır. Mahmood [51] ve Ma vd. [52] ise Amerika Birleşik Devletleri'nde bulunan sekiz kollu bir dönel kavşağı çalışmalarında konu edinmiştir. Çalışmaların çoğunda kısmi denetimli sinyalize dönel kavşakların, kavşak kol sayısı arttığında dahi başarılı sonuçlar verdiğinden bahsedilmiştir.

Çalışmalara konu olan dönel kavşaklar, bir, iki ya da üç şeritlidir. Fortuijn [36] k1smi denetimli sinyalize dönel kavşak yönteminin iki şeritli dönel kavşaklarda küçük akıma sahip kolun kapasitesini \% 15 ile $\% 45$ artıracağını ve ağır yüklü durumlarda tüm dönel kavşakta bekleme süresini $\% 20$ ile \% 50 azaltacağını bildirse de tek şeritli dönel kavşakların kapasitesi üzerine bir etkisi olmadığına dair göstergeler olduğundan bahsetmiş, yalnızca tek şeritli dönel kavşaklarda gecikmenin daha dengeli dağıldığını söylemiştir. Fakat bu sonucun aksine Martin-Gasulla vd. [48, 49], tek şeritli dönel kavşaklarda kapasitenin arttığını ve bu artışın, araştırma yapılan dönel kavşaklarda en iyi sinyalizasyon parametreleri kullanıldığında \%25 ve \%56 olarak gözlendiğini ve kapasite artışının çakışan akımın 500 taşıt/saat'i aştığı durumlarda anlamlı olduğunu belirtmiştir. Dahası, Natalizio [23] tek şeritli kısmi denetimli sinyalize dönel kavşaklarda sinyalize kolun doygunluk derecesi 0.6 'dan az olduğunda iyi, 0.7 'den az olduğunda tolere edilebilir sonuçlar verdiğinden bahsetmiştir. Ayrıca; Natalizio [23], Hummer vd. [47] ve Martin-Gasulla vd. [48] çalışmalarında tek şeritli dönel kavşaklar için kısmi denetimli sinyalize dönel kavşak yönteminin faydalı olabileceği akım kombinasyonlarını belirtmişlerdir. Bunlara ek olarak Hummer vd.' nin [47] çalışmasında iki şeritli dönel kavşaklarda uygulanacak kısmi denetimli sinyalizasyon için uygun akım kombinasyonlarına da yer verilmiştir. Natalizio’nun [23] çalışmasına göre tek şeritli dönel kavşaklarda kısmi denetimli sinyalizasyon, gecikme yaşayan kolun akımı ve bu kolun önünde sirküle olan akımın toplam 1300-1400 taşıt/saat olduğu durumlarda gerekli olur ve bu toplam akım değeri 1550-1650 taş1t/saat değerini geçtiğinde kısmi denetimli sinyalizasyonun etkisi kaybolmaya başlar. Benzer bir çalışma yapan MartinGasulla vd. [48] ise kontrol kolundaki akım talebi 800 taşıt/saat değerinin üzerindeyse kontrol kolu ve sirkülasyon akımı talebinin toplamı 1750 taşıt/saat değerini aştığında kısmi denetimli sinyalizasyonun faydalarının ortadan kalktığı sonucuna varmıştır. Çok şeritli dönel kavşaklar üzerine çalışmalar yapan araştırmacılar, kısmi denetimli sinyalize dönel kavşaklar hakkında olumsuz bir görüş belirtmemişlerdir. Araştırmacıların elde ettiği sonuçlara bakıldığında, kısmi denetimli sinyalize dönel kavşakların başarımı üstünde kollardan gelen talebin, kolların akım/kapasite oranının ve yaklaşım kolları önünde sirküle olan akımın önemli olduğu görülmektedir.

\subsection{Sinyalizasyon kurulan kol sayıs}

Kısmi denetimli sinyalize dönel kavşaklarda genellikle kolların biri sinyalize edilse de birden fazla kolda sinyalizasyon kullanılabilir. Geers vd. [45] Avustralya'da bulunan üç kollu Yallah dönel kavşağının iki kolunda sinyalizasyon kullanılan bir çalışma yapmışlardır. $\mathrm{Bu}$ çalışmada, kısmi denetimli sinyalize dönel kavşakların gecikmeleri çok ciddi seviyede düşürdüğü belirtilmiştir. An vd. [40] yaptıkları çalışmada kısmi denetimli sinyalize dönel kavşak olarak kullanılan Old Belair Yolu dönel kavşağının 
performansı AIMSUN ve Sidra Intersection kullanarak değerlendirilmiş, ayrıca iki kolu sinyalize edilen kısmi denetimli dönel kavşaklar için kullanılabilecek bir model önerisi sunulmuştur. Mahmood [51] ve Ma vd. [52] çalışmalarında sekiz kolu bulunan dönel kavşağın tüm kollarına detektörler yerleştirmiş, sinyalize olacak kol, kuyruk detektörlerinden gelen yanıta göre belirlenmiştir. Her iki çalışma sonucunda zirve saatte, gecikmede \%30'un üstünde ve ortalama kuyruk uzunluğunda \%40'a yakın düşüş gözlenmiştir. Ancak artan dönel kavşak elemanı sayısının, kurulum ve bakım maliyetleri gibi maliyetleri artıracağ göz önünde bulundurulmalı, bu tür uygulamalar yapılmadan önce detaylıca değerlendirilmelidir.

\subsection{Detektör yerleşimi ve sinyal süreleri}

Detektörün yerleşimi ve sinyal süreleri, kısmi denetimli sinyalize dönel kavşakların başarımını etkileyen en önemli parametrelerdendir. Detektörün yeri doğru şekilde belirlenemediğinde kritik kuyruk tespitinde aksamalar meydana gelebilir ve aşırı gecikmeye maruz kalan yaklaşım kolu, bu yöntemden yeterince faydalanamayabilir. Sinyal süresinin iyi ayarlanmadığı durumlarda ise sinyalize kol aşırı gecikmeye maruz kalabilir. $\mathrm{Bu}$ sebepler göz önünde bulundurulduğunda, kısmi denetimli sinyalize dönel kavşakların en iyi performansı gösterebilmesi için uygun detektör yerleşimi ve sinyal süresi seçimi oldukça önemlidir. $\mathrm{Bu}$ değerler yöresel faktörlere göre değişiklikler gösterebilir. Akçelik [33, 35], çalışmalarında devre süresi için detaylı analizine yer vermiş, uygun detektör mesafesi aralığından bahsetmiş ve Avustralya'nın Melbourne şehrinde bulunan kısmi denetimli sinyalize dönel kavşaklarda kullanılan parametrelerin bir tablosunu sunmuştur. Fortuijn [36] de çalışmasında detektör yerleşimi ve bu yerleşime göre sabit zamanlı kırmızı sinyal süreleri gibi detaylara yer vermiştir. Ayrıca Akçelik [35], çalışmasında sekiz farklı sinyalizasyon alternatifini kullanmış ve kısa devre sürelerinin uzun devre sürelerine göre daha iyi kavşak performansı sunduğu sonucuna varmıştır. Natalizio [23], tek şeritli dönel kavşaklarda uygulanacak kısmi denetim için en iyi kapasite ve performans sonucu veren parametreleri belirtmiştir. Akçelik [33] ve Natalizio' nun [23], çalışmalarında bahsettiği parametrelere Tablo 3'te yer verilmiştir. Bunun dışında Natalizio [23], aynı çalışmada şu sonuçlara da varmıştır;

-Daha yüksek minimum boş ve kırmızı süreler, daha kısa kuyruk detektörü mesafesine göre kontrol yaklaşımının kapasitesi ve performansı üzerinde daha olumlu bir etkiye sahiptir.

- Daha kısa bir kuyruk detektörü mesafesi, sinyalize yaklaşımın kapasitesi ve performansı üzerinde, daha yüksek minimum boş ve kırmızı sürelere göre daha az etkiye sahiptir.

\subsection{Klsmi denetimli sinyalize dönel kavşakların gecikme üzerine etkisi}

Kavşakların performansını değerlendirmek için çeşitli parametreler kullanılmaktadır. Bunların başında ise gecikme gelmektedir. Gecikme, bir kavşağa yaklaşan taşıtın çeşitli sebeplerle kavşakta kaybettiği ve yolculuk süresinin uzamasına neden olan sürelerin toplamı olup kavşak performansı değerlendirmesinde kullanılan önemli bir parametredir.

Tablo 3. Kısmi denetimli sinyalize kavşaklar için önerilen optimum parametreler

\begin{tabular}{|c|c|c|}
\hline Çalışma & Parametre & $\begin{array}{l}\text { Önerilen } \\
\text { Değer }\end{array}$ \\
\hline \multirow{3}{*}{ Natalizio [23] } & $\begin{array}{l}\text { Kuyruk } \\
\text { detektörü } \\
\text { mesafesi }\end{array}$ & $60 \mathrm{~m}$ \\
\hline & $\begin{array}{l}\text { Minimum boş } \\
\text { süre }\end{array}$ & $20 \mathrm{~s}$ \\
\hline & $\begin{array}{l}\text { Minimum } \\
\text { kırmızı süre }\end{array}$ & $20 \mathrm{~s}$ \\
\hline \multirow{9}{*}{ Akçelik [33] } & Sinyalize kol & \\
\hline & $\begin{array}{l}\text { Sinyalizasyonun } \\
\text { dur çizgisine } \\
\text { olan uzaklığ }\end{array}$ & $14-24 \mathrm{~m}$ \\
\hline & $\begin{array}{l}\text { Minimum boş } \\
\text { sinyal süresi }\end{array}$ & $20-50 \mathrm{~s}$ \\
\hline & $\begin{array}{l}\text { Minimum } \\
\text { kırmızı sinyal } \\
\text { süresi }\end{array}$ & $10-20 \mathrm{~s}$ \\
\hline & $\begin{array}{l}\text { Maksimum } \\
\text { kırmızı sinyal } \\
\text { uzatma süresi }\end{array}$ & $20-60 \mathrm{~s}$ \\
\hline & Kontrol Kolu & \\
\hline & $\begin{array}{l}\begin{array}{l}\text { Detektörün } \\
\text { çizgisine } \\
\text { uzaklığ }\end{array} \\
\text { olan }\end{array}$ & $50-120 \mathrm{~s}$ \\
\hline & $\begin{array}{l}\text { Kuyruk } \\
\text { detektörü boşluk } \\
\text { süresi }\end{array}$ & $3.0-3.5 \mathrm{~s}$ \\
\hline & $\begin{array}{l}\text { Kuyruk } \\
\text { detektörü } \\
\text { işgaliye süresi }\end{array}$ & $4.0-5.0 \mathrm{~s}$ \\
\hline
\end{tabular}

Gecikmenin yanı sıra hizmet seviyesi, kapasite, kuyruk uzunluğu, yolculuk süresi, durma sayısı, yakıt tüketimi, emisyon değerleri gibi parametreler de kavşakların performanslarını değerlendirmek amacıyla kullanılmaktadır. $\mathrm{Bu}$ literatür araştırmasına konu olan çalışmalarda da çeşitli parametreler kullanılmıştır. Ancak, temel olarak performans parametrelerinin hepsinin gecikmeyle ilintili olması ve çalışmaların hemen hemen hepsinde ortak parametre olması sebebiyle bu araştırmada kısmi denetimli sinyalize dönel kavşakların etkinliğini belirtmek için gecikme süreleri baz alınmıştır. Daha önce bahsedildiği gibi Fortuijn [36] çalışmasında iki şeritli dönel kavşaklarda gecikmede \%20 ile $\% 50$ arasında azalma olacağından bahsetse de tek şeritli dönel kavşaklarda kısmi denetimli sinyalizasyonun kapasite üzerinde bir etkisi olmayacağına dair göstergeler bulunduğunu belirtmiştir. Bunun dışında Buasali [46], yaptığı çalışmada gecikme sürelerinin kararsız hale geldiğini, bazı durumlarda ise artış gösterdiğini ve sinyalizasyonun teorik faydalarının gözlenemediğinden 
bahsetmiştir. Abdelfatah ve Alozn [42], çeşitli akım kombinasyonları altında kısmi denetimli sinyalize dönel kavşakların olumlu ve olumsuz etkiler doğurduğunu, yaklaşım kollarından gelen akımların eşit dağıldığında geleneksel dönel kavşakların daha iyi sonuç verdiğini ve bu sebeple yöntemin, sadece bir kolda ana akım olan ve diğer kolların görece düşük akım değerlerine sahip olduğu durumlarda kullanılması gerektiğini bildirmiştir. Akçelik [33] tarafindan gerçekleştirilen vaka çalışmasına bakıldığında ortalama gecikmede $\% 20$ düşüş gözlenmiştir. Akçelik [35] tarafindan gerçekleştirilen bir diğer vaka çalışmasında ise gecikme süresi yıllık bazda yaklaşık \%70 azalma göstermiştir. Mosslemi [44], yaptı̆̆ çalışmada Norveç'te bir koridoru konu edinmiş ve simülasyon sonucu dengesiz akımdan etkilenen kavşak için en iyi senaryo ile mevcut durum kıyaslandığında gecikmede yaklaşık \%90'lık bir iyileşme olduğundan bahsetmiştir. Bu sonucun yanı sıra koridor için de gecikme süresi ve diğer parametrelerde iyileşme görülmüştür. Ancak bu çalışma değerlendirilirken dengesiz akım bulunan kavşakta sinyalizasyonun yanı sıra mevcut durumda bulunmayan bir baypas şeridi kullanılarak geometrik iyileştirmeden de faydalanıldığg göz önünde bulundurulmalıdır. Geers vd. [45], tek şeritli dönel kavşakta zirve saatte gecikme değerinde \%85'e varan azalma gözlemlemiştir. Hummer vd. [47] gecikmenin tek şeritli ve çift şeritli dönel kavşaklarda sinyalizasyon olmayan duruma göre akım değerlerine bağlı olarak 100 saniye/binek oto'ya varan düşüşler olduğunu belirtmiştir. Martin-Gasulla vd. [48, 49], gecikme değerinin tek şeritli dönel kavşaklarda akım taleplerine bağlı olarak \%60'a kadar iyileşme gösterebileceğinden bahsetmiştir. Duan vd. [50], gecikme süresinde \%25.7' ye varan düşüş olduğundan bahseden bir çalışma yapmıştır. Mahmood [51] ve Ma vd. [52] ise gecikme süresinde zirve saatte \%30’u aşkıı düşüş olduğunu belirtmiştir. Elde edilen sonuçlar incelendiğinde, birkaç çalışmada olumlu olmayan sonuçlar elde edilse de kısmi denetimli sinyalize dönel kavşaklar, genel olarak kavşaklarda meydana gelen gecikmeyi iyileştirecek sonuçlar sunmuştur.

\subsection{Kısmi denetimli sinyalize dönel kavşakların çevresel ve ekonomik etkileri}

Kavşaklarda yaşanan zaman kayıpları ulaşımı sekteye uğratmakla birlikte görünmeyen başka olumsuz sonuçlar da doğurur. Yakıt sarfiyatının ve zararlı gazların salınımının artışı bunlar arasında gösterilebilir. Bu çalışmanın bir önceki maddesinde de bahsedildiği üzere, kısmi denetimli sinyalize dönel kavşaklar genellikle gecikme değerlerini iyileştiren sonuçlar vermektedir. Gecikmenin azalmasına bağlı olarak durma süresi, durma sayısı, yolculuk süresi gibi parametrelerde de azalma görülmektedir. Böylece harcanan yakıt ve salınan gaz miktarında da iyileşmeler meydana gelmektedir. Ancak literatürde kısmi denetimli sinyalize dönel kavşakların bu etkilerine pek değinilmemiştir. Yapılan az sayıdaki çalışmaya bakıldığında, Sides [24], yapılan modelleme sonucu projenin ilk 20 yilda atmosfere salınan kirletici gazların 493,456 kg azalacağından bahsetmiştir. Bu konu üstünde çalışan isimlerden olan Akçelik [33], $\mathrm{CO}_{2}$ salınımında \%5' e yakın bir azalma olduğunu bildirmiştir.
Yine Akçelik [35,41], çalışmalarında belirttiği üzere, optimum senaryoda $\mathrm{CO}_{2}$ salınımında yıllık bazda yaklaşık $\% 23$, yakıt sarifyatında \%22' ye varan iyileşmeler gözlemlemiştir. Ayrıca Akçelik [33, 35, 41], bu çalışmalarda operasyonel maliyetlerde ise sirasiyla $\% 7, \% 36$ ve $\% 38$ ' e yakın düşüş olduğunu belirtmiştir. Fernandes vd. [53], kısmi denetimli sinyalze dönel kavşakların koridorlardaki trafikle ilgili maliyetleri azaltmak üzerindeki etkisini araştırmışlardır. Bunun için Portekiz'in Guimares şehrinde bulunan, dört dönel kavşak ve bir sinyalize kavşaktan oluşan koridor üzerinde çalışmışlardır. Koridorda iki dönel kavşakta kısmi denetimli sinyalizasyon kullanılmıştır. Çalışmada emisyon değerleri ve gürültü maliyeti gibi parametreler araştırılmış, bu değerlerin zararlarını azaltacak optimum kısmi denetimli sinyalize dönel kavşak modeli geliştirilmiştir. Farklı trafik yükleri ve dönüş yüzdeleri senaryoları altında yöntemin başarısı araştırılmış ve sinyalizasyondan önceki ve sonraki durum karşılaştırılmıştır. Çalışmaya göre, mevcut trafik talebi altında, toplam maliyetlerin sinyalizasyonsuz duruma kıyasla \%11'e kadar düşüş sağladığı sonucuna varılmıştır. Ayrıca, gürültüye bağlı maliyetlerde de optimum durum altında \%11 düşüş gözlemlenmiştir. Bu konu hakkında az sayıda çalışmanın sonuçlarına bakıldığında, kısmi denetimli sinyalize dönel kavşakların çeşitli ekonomik ve çevresel parametrelerde de iyileşme sağladığı sonucuna varılmıştır.

\section{Sonuçlar}

Kısmi denetimli sinyalize dönel kavşakların performansının incelendiği bu literatür taramasında, kısmi denetimli sinyalize dönel kavşakların genel olarak kavşak performansını iyileştiren sonuçlar verdiği görülmüştür. $\mathrm{Bu}$ yöntem ile gecikme süresi, yolculuk süresi, durma sayıs1, kuyruk uzunluğu, kapasite, hizmet seviyesi ve az sayıdaki çalışmada da yakıt sarfiyatı, emisyon değerleri ve işletme maliyetleri gibi performans parametrelerinde iyileşmelerden bahsedilmiştir. $\mathrm{Bu}$ sonuçlara bakıldığında yöntem, dönel kavşakların yönetimi adına alternatif bir çözüm olarak kullanılabilir. Ancak literatüre göre bu yöntem, dönel kavşaklarda meydana gelen dengesiz akımları yönetmek için kullanıldığından yöntemin başarımı; yaklaşım kollarından gelen ve sirküle olan akımlar, hacim/kapasite oranı gibi parametrelerin yanı sıra kullanılacak detektörün veya detektörlerin yeri, sinyalizasyonda kullanılacak kırmızı ve boş sinyal süreleri gibi parametrelerle de direkt olarak ilintilidir. Sürücü davranışlarının da yörelere göre değişebilecek olması, takip aralığı ve kritik boşluk gibi parametrelerin de göz önünde bulundurulmasını gerektirmektedir. Bu sebeple yöntemden en yüksek fayda sağlamak için detaylı ve tekrarlı çalışmalar hem sahada hem bilgisayar ortamında yapılmalıdır.

Literatüre bakıldığında çalışmaların genellikle izole kavşaklar üzerinde yoğunlaşmış olduğu ve kısmi denetimli sinyalize dönel kavşakların koridor performanslarına çok fazla değinilmediği görülmüştür. $\mathrm{Bu}$ sebeple gelecek çalışmalarda yöntemin koridorlar üzerindeki etkisi de araştırılacak konulardan biri olabilir.

Bunlara ek olarak, ülkemizde sinyalize dönel kavşakların yoğun bir biçimde kullanıldığı düşünüldüğünde, bu 
yöntemin ülkemizdeki dönel kavşaklar üstünde uygulanabilirliği adına çalışmalar yapılmalıdır.

\section{Çıkar çatışması}

Yazarlar çıkar çatışması olmadığını beyan etmektedir.

\section{Benzerlik oranı (iThenticate): \%19}

\section{Kaynaklar}

[1] KGM, Karayolları Tasarım El Kitabı, Karayolları Genel Müdürlüğü, Ankara, 2016.

[2] KGM, Trafik Kazaları Özeti 2019. https://www.kgm. gov.tr/SiteCollectionDocuments/KGMdocuments/Traf ik/TrafikKazalariOzeti2019.pdf, Erişim tarihi 10 Ekim 2020.

[3] Federal Highway Administration, Intersection Safety. https://highways.dot.gov/research/researchprograms/s afety/intersection-safety, Erişim tarihi 10 Ekim 2020.

[4] European Commission, Annual Accident Report, 2018. https://ec.europa.eu/transport/road_safety/sites/roadsaf ety/files/pdf/statistics/dacota/asr2018.pdf, Erişim tarihi 10 Ekim 2020

[5] KGM, Karayolu Trafik Güvenliği El Kitabı. Trafik Şubesi Müdürlüğü, Ankara. 2007.

[6] B.W. Robinson, L. Rodegerdts, W. Scarborough, W. Kittelson. Roundabouts: An Informational Guide, Federal Highway Administration, Virginia, USA. 2000.

[7] AASHTO, A Policy on Geometric Design of Highways and Streets. The American Association of State Highway and Transportation Officials, AASHTO Green Book, Washington DC. 2011.

[8] J. Bared, W. Prosser and C. Esse. State-of-the-art design of roundabouts. Journal of the Transportation Research Board, 1579, 1-10. 1997.

[9] A. Flannery, T.K. Datta. modern roundabouts and traffic crash experience in United States. Transportation Research Record, 1553(1), 103-1091. 1996.

[10] R. A. Retting, B. N. Persaud and P. E. Garder. Crash and injury reduction following the installation of roundabouts in the United States. American Journal of Public Health, 91 (4), 628-631. 2001.

[11] KGM, Modern Dönel Kavşaklar Planlama, Tasarım ve Uygulama Rehberi. Stratejik Planlama Şubesi Müdürlüğü, Ankara. 2018.

[12] M. Valdez, Effects of unbalanced approach volumes on roundabout operations. ETD Collection for University of Texas, El Paso. 2010.https://scholarworks.utep.edu/ open_etd/2603

[13] K.W. Huddart, Signaling of Hyde Park corner, elephant and castle and other roundabouts. PTRC 11th Summer Annual Meeting, Proceedings of Seminar K, 193-208. 1983.

[14] J. Krogscheepers, C. Roebuck, Unbalanced traffic volumes at roundabouts. In: Fourth International Symposium on Highway Capacity, Hawaii, USA. 2000.

[15] A. Tunç, Trafik Mühendisliği ve Uygulamaları. 1. Baskı, Asil Yayın Dağıtım, 790, 2003.
[16] R. Akçelik, Roundabouts with unbalanced flow patterns. Presented at the ITE Annual Meeting and Exhibit, Lake Buena Vista, Florida. 2004.

[17] T. Aydemir ve S. Tanyel, 2005. Çok şeritli dönel kavşaklar üzerinde OD matrisinin etkisi, 6. Ulaştırma Kongresi, 23-25 Mayis, İstanbul.

[18] Main Roads Western Australia, Guidelines for the Selection of Intersection Control, 2015.

[19] C. R. Stevens, Signals and meters at roundabouts. In: The 2005 Mid-continent Transportation Research Symposium, Ames, Iowa, USA. 2005.

[20] Department for Transport. Local Transport Note 1/09, Signal Controlled Roundabouts. 2009.

[21] T. Tollazzi Alternative Types of Roundabouts at Development Phases. In: Alternative Types of Roundabouts. Springer Tracts on Transportation and Traffic, 6. Springer, Cham, Switzerland. 2015.

[22] M. S. Hallworth, Signalling Roundabouts. Traffic Engineering and Control 33.6, 354-363. 1992.

[23] E. Natalizio, Roundabouts with Metering signals. Presented at ITE Annual Meeting, Melbourne, Victoria, Australia. 2005.

[24] K. Sides, Assessing the clearwater beach entryway roundabout. In: Institute of Transportation Engineers 2000 Annual Meeting and Exhibit, Tennessee, USA. 2000.

[25] R. Akçelik, An Investigation of the performance of roundabouts with metering signals. Presented at TRB National Roundabout Conference, Kansas City, Missouri, USA. 2008.

[26] N.Z. Herald, Tauranga's Barkes Corner roundabout metering to begin next week. https://www.nzherald. co.nz/bay-of-plenty times/news/taurangas-barkescorner-roundabout-metering-to-begin-next week/abo24wdrwıv4gvbu3qıtbphavm/. Erișim tarihi 13 Ekim 2020.

[27] WSDOT, SR 240 - Steptoe roundabout traffic metering.https://wsdot.wa.gov/projects/sr240/steptoeroundabout/home. Erişim tarihi 13 Ekim 2020.

[28] New Zealand Transport Agency, SH2 Elizabeth Street roundabout metering. https://www.nzta.govt.nz/ projects/sh2-elizabeth-street-roundabout-metering. Erişim tarihi 13 Ekim 2020.

[29] KTVZ, Bend reviewing results of metered roundabout test.https://ktvz.com/videos/localvideos/2020/04/23/be nd-reviewing-results-of-metered-roundabout-test/. Erişim tarihi 13 Ekim 2020.

[30] Z. Çakıcı, Sinyalize dönel (yuvarlakada) kavşakların tasarım esaslarının araştırılması, Yüksek Lisans Tezi, Pamukkale Üniversitesi Fen Bilimleri Enstitüsü, Denizli. 2014.

[31] L. Rodegerdts, J. Bansen, C. Tiesler, J. Knudsen, E. Myers, M. Johnson, M. Moule, B. Persaud, C. Lyon, S. Hallmark, H. Isebrands, R. Crown, B. Guichet and A. O'Brien. NCHRP Report 672: Roundabouts: An Informational Guide, 2nd ed. Transportation Research Board of the National Academies, Washington, D.C., USA. 2010. 
[32] VicRoads, Supplement to austroads guide to traffic management Part 6: Intersections, Interchanges and Crossings (2013). 2015.

[33] R.Akçelik, Capacity and performance analysis of roundabout metering signals. Presented at TRB National Roundabout Conference, Vail, Colorado, USA. 2005.

[34] New Zealand Transport Agency, Traffic Note 60, 2011. https://www.nzta.govt.nz/assets/resources/trafficnotes/docs/traffic-note-60.pdf. Erişim tarihi 14 Ekim 2020.

[35] R. Akçelik, Roundabout metering signals: capacity, performance, and Timing. Presented at 6th International Symposium on Highway Capacity, TRB, Stockholm, Sweden. 2011.

[36] L. G. H. Fortuijn, Robustness of roundabout metering systems (RMS). In Transportation Research Board 4th International Roundabout Conference, Seattle, USA. 2014.

[37] Austroads, Guide to Traffic Management Part 6: Intersections, Interchanges and Crossing. 2017.

[38] Google Maps, https://www.google.com/maps/@ 38.0056606,145.0862517,3a,73.8y,237.64h,91.36t/dat $\mathrm{a}=$ !3m6!1e1!3m4!1sDQP_PEZLxIkryipX06snCQ!2e0 !7i13312!8i6656. Erişim tarihi 15 Ekim 2020

[39] M. Zadid and W. Yue, Comparison of a roundabout model using aaSIDRA and PARAMICS. Papers of the 32nd Australasian Transport Research Forum ATRF, Auckland, New Zealand. 2009.

[40] H. K. An, W. L. Yue and B. Stazic, Dual signal roundabout evaluation in Adelaide using SIDRA and AIMSUN. Road \& Transport Research: A Journal of Australian and New Zealand Research and Practice, 26(2), Jun 2017, 36-49. 2017.

[41] R. Akçelik, Operating Cost, Fuel consumption and pollutant emission savings at a roundabout with metering signals. Presented at the ARRB 22nd Conference, Canberra, Australia. 2006.

[42] A. Abdelfatah and M. Alozn, Comparing roundabout and metered roundabout performance under different traffic conditions. International Journal of Structural and Civil Engineering Research, 8(2), 178-182. 2019.

[43] H. K. An, W. L. Yue and B. Stazic, Estimation of vehicle queuing lengths at metering roundabouts. Journal of Traffic and Transportation Engineering, 4, 545-554. 2017.
[44] M. Mosslemi, Using metering signals at roundabouts with unbalanced flows to improve the traffic condition: the case study of kannik area in Stavanger (Dissertation). Retrieved from http://urn.kb.se/ resolve?urn=urn:nbn:se:liu:diva-16429. 2008.

[45] D. G. Geers, P. Tyler, B. Hengst, E. Huang and D. Quail, Enhanced roundabout metering. Papers of the 16th ITS World Congress and Exhibition on Intelligent Transport Systems, Stockholm, Sweden. 2009.

[46] A. Buasali, broadening understanding of roundabout operation analysis: planning-level tools and signal application, Civil Engineering Theses, Dissertations, and Student Research. 113. University of Nebraska Lincoln, USA. 2017.

[47] J. E. Hummer, J. S. Milazzo II, B. Schroeder and K. Salamadi, Potential for metering to help roundabouts manage peak period demands in the United States. In Transportation Research Record: Journal of the Transportation Research Board, 2402, Transportation Research Board of the National Academies, Washington, D.C., USA, 56-66. 2014.

[48] M. Martin-Gasulla, A. Garcia, A.T. Moreno, Benefits of metering signals at roundabouts with unbalanced flow:patterns in Spain. Transportation Research Record 2585, 20-28. 2016.

[49] M. Martin-Gasulla, A. Garcia, A.T. Moreno and C. Llorca, Capacity and operational improvements of metering roundabouts in Spain. Transportation Research Procedia 15, 295-307. 2016.

[50] Y. Duan, X. Qu, S. Easa and Y. Yan, Optimizing total entry delay at roundabouts with unbalanced flow: A dynamic strategy for smart metering. IET Intelligent Transport Systems. 13. 485-494. 2018. https://doi.org/10.1049/iet-its.2018.5180

[51] K. Mahmood, Improving roundabout performance using roundabout metering technique. Electronic Thesis or Dissertation. University of Akron, 2016.

[52] X. Ma, P. Yi, and V. Bolla, Priority metering control for an urban circular intersection. Civil Engineering Journal; Prague Iss. 2,292-304. 2019.

[53] P. Fernandes, J. Teixeira, C. Guarnaccia, J.M. Bandeira, E. Macedo and M.C. Coelho, The Potential of metering roundabouts: influence in transportation externalities. Transportation Research Record, 2672(25), 21-34. 2018. 